\title{
Breast Density: Does It Vary among the Main Ethnic Groups in Malaysia?
}

\author{
Kanaga Kumari Chelliah ${ }^{1}$, Noor Shatirah Mohd Fandi Voon ${ }^{1}$, Hanizan Ahamad ${ }^{2}$ \\ ${ }^{1}$ Diagnostic Imaging and Radiotherapy Programme, Health Sciences Faculty, \\ National University of Malaysia, Kuala Lumpur, Malaysia \\ ${ }^{2}$ Radiology Department, University Malaya Medical Centre, Kuala Lumpur, Malaysia \\ Email: kanagakkc@yahoo.com
}

Received September 20, 2013; revised October 20, 2013; accepted October 27, 2013

Copyright (C) 2013 Kanaga Kumari Chelliah et al. This is an open access article distributed under the Creative Commons Attribution License, which permits unrestricted use, distribution, and reproduction in any medium, provided the original work is properly cited.

\begin{abstract}
Breast cancer is one of the common cancers among Malaysians and there are associated risk factors which include breast density. Therefore, this study was done to determine the association of breast cancer risks among ethnic groups in relation to breast density. Mammography was done on 300 women with equal numbers of Malays, Chinese and Indians with a mean age of $53.35 \pm 7.4$ years. Mammograms were evaluated using BI-RADS (Breast Imaging Reporting and Data System) protocol by two independent radiologists for breast density categorization. Chi-square analysis showed an association between breast density and age factor $(\mathrm{p}<0.05)$ whereas body mass index $(\mathrm{BMI})$ was inversely associated with breast density $(\mathrm{p}>0.05)$. There was significant difference in number of children and menopausal status $(\mathrm{p}<0.05)$. Results showed that $65 \%$ of Chinese subjects had denser breast density composition as to $50 \%$ in Malays and $35 \%$ in Indians. There was significant difference between breast density of three ethnic groups $(\mathrm{p}<0.05)$ with Chinese having 2.4 times denser breast $(\mathrm{OR}=2.45,95 \% \mathrm{CI}: 1.466$ - 3.948) followed by Malays $(\mathrm{OR}=1.020,95 \% \mathrm{CI}$ : $0.681-1.689)$ and lowest in Indians $(\mathrm{OR}=0.406,95 \% \mathrm{CI}: 0.247-0.668)$. Based on breast density, the Chinese are at a higher risk of developing breast cancer followed by Malays and lastly Indians.
\end{abstract}

Keywords: Breast Cancer; Ethnic Groups; Breast Density; Mammogram; BIRADS

\section{Introduction}

3525 women had been diagnosed with breast cancer in 2006 and represents $31 \%$ of the total number of cancer diagnosed in women [1]. Breast cancer is reported to be diagnosed at a tender age of 15 years in Malaysia and is common in all the ethnic groups in Malaysia. Age Standardized Incidence (ASR) for breast cancer in Malaysia was 39.3 in 100,000 populations with Chinese having the highest incidence rate (ASR 46.4 in 100,000 populations), followed by Indians (ASR 38.1 in 100,000 populations) and Malays (ASR 30.4 in 100,000 populations).

Mammography is an x-ray examination that utilizes low dose of radiation for imaging the breast in two projections and has the ability to detect 80 - 90 percent of breast cancer in women prior to having any symptoms. Mammography is also the gold standard for breast screening for women in their forties or older and is approved by Food and Drug Authority for early detection of micro calcification and masses. Besides it can be used to evalu- ate breast density and monitoring of treatment in patients.

Breast density is defined as tissue characteristics seen on mammogram, stroma and epithelial tissues of breast and are displayed as whitish grey due to the absorption of radiation and fatty area appears darker due to penetration of radiation. Variations in the characteristics of these tissues enable it to be categorized qualitatively and quantitatively to various breast density [2]. It is a problem in identifying cancer tissue in dense breast compared to less dense breast due to similar radiographic characteristic seen on mammograms [3]. The protocols used in categorization of breast density on mammograms are namely Wolfe parenchymal patterns, Tabar categorization and Breast Imaging Reporting and Data System (BIRADS). It is important that categorization of breast density evaluated on mammogram is able to predict risk of cancer $[4,5]$.

Other risk factors contributing to breast cancer are age, demographic location, early menarche, late menopausal age, pregnancy at a late age, obesity, alcohol consump- 
tion, radiation, hormone replacement therapy (HRT) and use of contraceptive pills [6,7].

Global studies had proven the association between breast density and breast cancer whereby dense breast is at a higher risk of breast cancer and varies with ethnicity $[8,9]$. Thus, this study was conducted to determine the association of breast cancer risk among the three different ethnic groups in Malaysia with relation to breast density.

\section{Materials and Methods}

\subsection{Subjects}

Across-sectional study was done at University Malaya Medical Centre after obtaining ethical approval. Subjects were Malaysian women aged 40 - 70 years from the three ethnic groups: Malays, Chinese and Indians while subjects with breast cancer and breast augmentation were excluded from the study. A total of 300 women were recruited with equal distribution of ethnic groups and informed consent was obtained before commencement of the study.

\subsection{Data Collection}

The equipment used was a Siemens Novation DR digital mammography system with exposure parameters: 26 to $32 \mathrm{kVp}$, tungsten $(\mathrm{W})$ anode tube and rhodium $(\mathrm{Rh})$ filter. All subjects gave consent before acquisition of mammography in the auto exposure mode. Two projections were taken, craniocaudal (CC) and medio-lateral oblique (MLO) for both right and left breast. Interpretation of mammograms were done by two independent radiologists with a minimum of five years experience based on Breast Imaging Reporting and Data System (BI-RADS) protocol which used four categories of breast tissues; almost entirely fat (I), scattered fibroglandular tissue (II), heterogeneously dense (III), and extremely dense (IV). Both BI-RADS I and BI-RADS II were clustered and categorized as fatty breast while BI-RADS III and BI-RADS IV as dense breast. A questionnaire related to demographic data was completed by the subjects which consisted of: age, ethnicity, marital status, body mass index (BMI), height, weight, age at menarche, age at first pregnancy, number of children, family history of breast cancer, menopausal status, and use of hormone replacement therapy (HRT).

\subsection{Data Analysis}

Statistical analyses were done using "Statistical Package for Social Sciences" (SPSS) with significance of p-value $<0.05$. Descriptive analyses were presented in frequency and percentage. Bivariate analyses were done to evaluate the association of breast cancer risks to breast density and the correlation of breast density among the three ethnic groups.

\section{Results}

Categorization of breast density based on mammograms by both radiologist are shown in Figure 1. There was a good agreement between the radiologists using Kappa ( $\kappa$ $=0.674)$.

Table 1 displayed the data obtained from the three main ethnic groups. The average age of Malays were lowest (51.77 years) compared to Chinese (55.24 years) and Indians (52.75 years) with a significant difference (p $=0.004)$. Besides, body mass index (BMI) of the three groups were significantly different $(\mathrm{p}<0.001)$. The Chinese showed normal BMI (22.63) while both Malays (27.27) and Indians (27.59) were obese. There was significance difference for number of children $(\mathrm{p}<0.001)$ and use of HRT ( $p=0.011)$ with Malays having highest average number of children ( 2.80 children). There was no significant difference for age at menarche $(\mathrm{p}=0.905)$, age at first pregnancy $(p=0.414)$, family history of breast cancer, menopausal and marital status $(p>0.05)$.

Majority of Chinese women were categorized with dense breast (64\%) $(\mathrm{OR}=2.405,95 \%$ CI: 1.466 - 3.948) and an equal distribution between both dense and fatty counterparts were shown in Malays $(\mathrm{OR}=1.020,95 \% \mathrm{CI}$ : 0.681 - 1.689) (Figure 2). Most Indians, were categorized in fatty breast composition $(65 \%)(\mathrm{OR}=0.406$, 95\% CI: $0.2407-0.668)$. There was significant difference in the three ethnic groups for breast density $(p<$ $0.05)$.

\section{Discussion}

Breast density composition was divided into two groups; of BI-RADS I and BI-RADS II (fatty breast) whilst BI-RADS III and BI-RADS IV (dense breast). There was a significant difference between the three ethnic groups with Chinese having the highest breast density composition followed by Malays and Indians. Jamal N (2005) stated Chinese had the highest glandularity (50.9\%) fol-

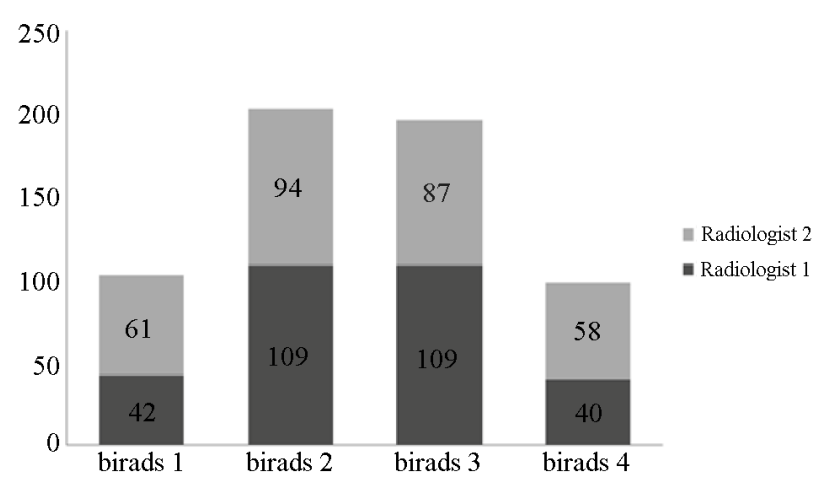

Figure 1. Categorization of breast density using BIRADS. 
Table 1. Association of factors of breast cancer risk between three ethnic groups.

\begin{tabular}{|c|c|c|c|c|}
\hline & Malay & Chinese & Indian & p value ${ }^{* *}$ \\
\hline Total & 100 & 100 & 100 & \\
\hline Age (average) & $51.77^{*}$ & $55.24^{*}$ & $52.75^{*}$ & 0.004 \\
\hline Body mass index & $27.27^{*}$ & $22.63^{*}$ & $27.59^{*}$ & $<0.0001$ \\
\hline Age of first menarche & $13.10^{*}$ & $12.85^{*}$ & $13.00^{*}$ & 0.905 \\
\hline Age of first child birth & $26.54^{*}$ & $27.65^{*}$ & $26.41^{*}$ & 0.414 \\
\hline Number of children & $2.80^{*}$ & $1.97^{*}$ & $2.46^{*}$ & $<0.0001$ \\
\hline Age of menopause & $49.37^{*}$ & $50.0^{*}$ & $49.05^{*}$ & 0.094 \\
\hline Family history with breast cancer & & & & 0.835 \\
\hline Yes & $15(30.4 \%)$ & $14(37 \%)$ & $17(32.6 \%)$ & \\
\hline No & $85(33.9 \%)$ & $86(32.7 \%)$ & $83(33.8 \%)$ & \\
\hline Marital status & & & & 0.436 \\
\hline Single & $11(32 \%)$ & $8(24 \%)$ & $6(44 \%)$ & \\
\hline Married & $89(33.5 \%)$ & $92(34.2 \%)$ & $94(32.4 \%)$ & \\
\hline Menopausal status & & & & 0.217 \\
\hline Not yet & $35(25.6 \%)$ & $22(35.7 \%)$ & $29(40.7 \%)$ & \\
\hline Already menopause & $58(37.4 \%)$ & $74(33.3 \%)$ & $66(29.3 \%)$ & \\
\hline Not sure & $7(43.8 \%)$ & $4(25 \%)$ & $5(31.3 \%)$ & \\
\hline Intake of HRT & & & & 0.011 \\
\hline Never & $83(36.4 \%)$ & $69(30.3 \%)$ & $76(33.3 \%)$ & \\
\hline Did & $3(8.3 \%)$ & $19(52.7 \%)$ & $14(38.9 \%)$ & \\
\hline Using & $14(38.9 \%)$ & $12(33.3 \%)$ & $10(27.8 \%)$ & \\
\hline
\end{tabular}

*Average; ${ }^{* *}$ Chi square.

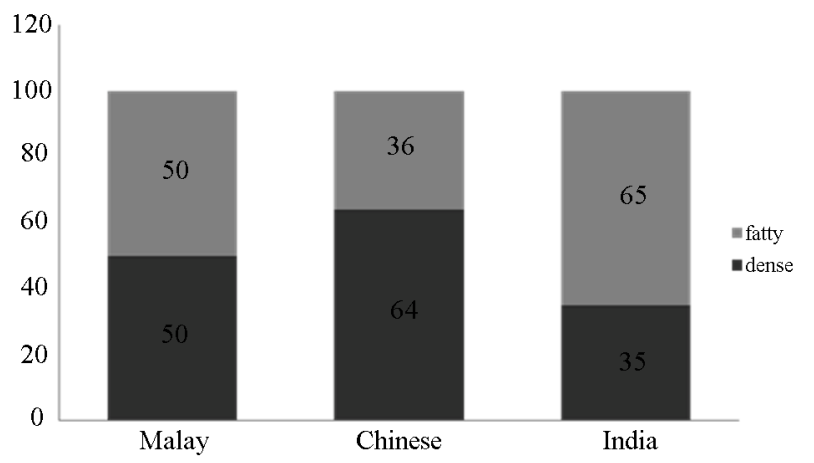

Figure 2. Breast density between three race groups.

lowed by Indians (48.1\%) and Malays (47.9\%), however there was no significant difference [10]. Previous studies have indicated, differences in breast density between ethnic groups may be due to addendum factors such as body mass index (BMI), hormonal and reproductive factors as well as environmental factors [8].

Based on this study, women from the three ethnic groups with an age of 50 and above had less dense breast compared to those younger due to hormonal changes [11] and depletion in breast glandular tissues and an escalation of adipose tissue percentage in breast [12]. Besides cancer detection rate is higher in women above the age of 50 years due to ease of interpretation on low density breast [3]. Nevertheless, an appropriate number of postmenopausal women, were shown to have dense breast pattern on mammograms indicating age is not a perfect surrogate for breast density [13].

As breast density was inversely related to BMI it is a non-dependable risk factor. Nevertheless, higher BMI increased breast cancer risk in postmenopausal women rather than premenopausal women [14]. Higher BMI in premenopausal women showed inverse correlation to breast cancer risk but positively correlated to postmenopausal women. In this study, Malays and Indians were in obese state but had less dense breast hence a lower risk factor which was coherent with Ursin et al. [15].

However in this study, Chinese women are more vulnerable to breast cancer due to their prolonged years of dense breast based on the menopausal age of the study. Early menarche was not significant for all the ethnic groups, which was in agreement with a previous studies $[16,17]$. However some studies reported that late menarche was associated with lower breast density and breast cancer risk as it may be due to the shorter span of exposure to estrogen hormone. Two studies had shown slight 
inverse association of breast density to late menarche age, but the relationship was not statistically significant $[17$, $18]$.

There was also no significant difference between first conceived age and breast density, however women who had their first born at the age of 26 and above tend to have dense breast and are at an increased risk of breast cancer [19]. The average number of children in this study was $2.41 \pm 1.62$ children, the risk decreases with $1-2$ children by $24 \%(95 \%$ CI: $7 \%-38 \%$ ) and $3 \%-4 \% 35 \%$ (95\% CI: 20\% - 47\%) [19].

History of breast cancer to breast density for all ethnic groups was not significant as there was a lack of subjects with history of breast cancer. It is stated that history of breast cancer was related to breast density as it is associated with genetic factor and it increases with increase in the number of family members and diagnosis before the age of 50 [20].

Hormone replacement therapy (HRT) usage was not significant to breast density in all ethnic groups, this may be due to the small sample size of 36 women who were on this therapy. Meanwhile, HRT increased the density by $17 \%-73 \%$ depending on the type of hormone consumed whilst women who excluded HRT will have a decrease in breast density with passing years [21].

\section{Acknowledgements}

Our sincere thanks to the ethics committee who approved the study, radiologists and radiographers who assisted in the study. Our greatest appreciation is to the subjects who voluntarily participated in this study.

\section{REFERENCES}

[1] Ministry of Health Malaysia, "Malaysian Cancer Statistic-Data and Figure," Peninsular Malaysia, National Cancer Registry, 2006.

[2] C. Byrne and C. Spernak, "What Is Breast Density?" Cambridge University Press, Cambridge, 2005.

[3] A. Butler, "Breast Disease and Mammography," Aids to Radiological Differential Diagnosis, Vol. 5, 2009, pp. 237-250.

[4] C. M. Vachon, C. H. Van Gils, T. A. Sellers, K. Ghosh, S. Pruthi, K. R. Brandt, et al., "Mammographic Density, Breast Cancer Risk and Risk Prediction," Breast Cancer Research, Vol. 9, 2007, pp. 217-226. http://dx.doi.org/10.1186/bcr1829

[5] R. W. Pinsky and M. A. Helvie, "Mammographic Breast Density: Effect on Imaging and Breast Cancer Risk," Journal of the National Comprehensive Cancer Network, Vol. 8, No. 10, 2010, pp. 1157-1164.

[6] I. T. Gram, Y. Bremnes, G. Ursin, G. Maskarinec, N. Bjurstam and E. Lund, "Percentage Density, Wolfe's and Tabar's Mammgraphic Patterns: Agreement and Association with Risk Factors for Breast Cancer," Breast Cancer
Research, 2005.

http://breast-cancer-research.com/content/7/5/R854

[7] L. T. Ernstoff, A. N. A. Tosteson, C. Kasales, J. Weiss, M. Goodrich, E. E. Hatch and P. A. Carney, "Breast Cancer Risk Factors in Relation to Breast Density (United States)," Cancer Causes and Control, Vol. 17, No. 10, 2006, pp. 1281-1290. http://dx.doi.org/10.1007/s10552-006-0071-1

[8] G. Maskarinec, I. Pagano, Z. Chen, C. Nagata and I. T. Gram, "Ethnic and Geographic Differences in Mammographic Density and Their Association with Breast Cancer Incidence," Breast Cancer Research and Treatment, Vol. 104, No. 1, 2007, pp. 47-56.

http://dx.doi.org/10.1007/s10549-006-9387-5

[9] V. A. McCormack, N. Perry, S. J. Vinnicombe and I. D. Santos Silva, "Ethnic Variations in Mammographic Density: A British Multiethnic Longitudinal Study," American Journal of Epidermiology, Vol. 168, No. 4, 2008, pp. 412-421. http://dx.doi.org/10.1093/aje/kwn169

[10] N. Jamal, "A Study of Breast Composition Using Radiographic Techniques," Tesis Dr. Fal, Fakulti Perubatan. Universiti Malaya, 2005.

[11] N. F. Boyd, H. Guo, L. J. Martin, L. Sun, J. Stone, E. Fischell, R. A. Jong, G. Hislop, A. Chiarelli, S. Minkin and M. J. Yaffe, "Mammography Density and the Risk, and Detection of Breast Cancer," New England Journal of Medicine, Vol. 356, No. 3, 2007, pp. 227-236. http://dx.doi.org/10.1056/NEJMoa062790

[12] D. Soares, M. Reid and M. James, "Age as Predictor Factor of Mammographic Breast Density in Jamaican Women," Clinical Radiology, Vol. 57, No. 6, 2002, pp. 472-476. http://dx.doi.org/10.1053/crad.2001.0873

[13] C. M. Checka, J. E. Chun, F. R. Schnabell, J. Lee and H. Toth, "The Relationship of Mammographic Density and Age: Implications for Breast Canccer Screening," American Journal of Roentgenology, Vol. 198, No. 3, 2012, pp. W292-W295. http://dx.doi.org/10.2214/AJR.10.6049

[14] C. L. Mulhall, "An Epidemiologic Study of Mammographic Density Measures and Common Polymorphisms in Gene of Lipoprotein Metabolism and the Growth Hormones Insuline Like Growth Factors I Axis," Tesis Dr. Fal, Universiti of Toronto, Kanada, 2005.

[15] G. Ursin, H. Ma, A. H. Wu, L. Bernstein, M. Salane, Y. R. Parisky, et al., "Mammographic Density and Breast Cancer in Three Ethnic Groups," Cancer Epidemiology, Biomarkers \& Prevention, Vol. 12, No. 4, 2003, pp. 332-338.

[16] Z. Chen, A. H. Wu, W. J. Gauderman, L. Bernstein, H. Ma, M. C. Pike and G. Ursin, "Does Mammography Density Reflect Ethnic Differences in Breast Cancer Incidence Rates?" American Journal of Epidermiology, Vol. 159, No. 2, 2003, pp. 140-147. http://dx.doi.org/10.1093/aje/kwh028

[17] D. Heng, F. Gao, R. Jong, E. Fishell, M. Yaffe, L. Martin, T. Li, J. Stone, L. Sun, J. Hopper and N. F. Boyd, "Risk Factors for Breast Cancer Associated with Mammographic Features in Singaporean Chinese Women," Cancer Epidemiology, Biomarkers \& Prevention, Vol. 13, No. 1, 2004, pp. 1751-1758.

[18] G. Maskarinec, L. Meng and G. Ursin, "Ethnic Differ- 
ences in Mammographic Densities," International Journal of Epidemiology, Vol. 30, No. 5, 2001, pp. 959-965. http://dx.doi.org/10.1093/ije/30.5.959

[19] C. G. Woolcott, K. Koga, S. M. Conray, C. Byrne, C. Nagata, G. Ursin, et al., "Mammographic Density, Parity and Age at First Birth, and Risk of Breast Cancer: An Analysis of Four Case-Control Studies," Breast Cancer Research and Treatment, Vol. 132, No. 3, 2012, pp. 1163-1171. http://dx.doi.org/10.1007/s10549-011-1929-9

[20] A. B. Crest, E. J. Aiello, M. L. Anderson, S. Diana and M. Buist, "Varying Levels of Family History of Breast Can- cer in Relation to Mammographic Breast Density (United Stated)," Cancer Causes Control, Vol. 17, No. 6, 2006, pp. 843-850.

http://dx.doi.org/10.1007/s10552-006-0026-6

[21] A. Y. El-Bastawissi, E. White, M. T. Mandelson and S. Taplin, "Reproductive and Hormonal Factors Associated with Mammographic Breast Density by Age (United States)," Cancer Causes and Control, Vol. 11, No. 10, 2000, pp. 955-963.

http://dx.doi.org/10.1023/A:1026514032085 